\title{
A Study of English Translation of Six Chapters of A Floating Life from the Perspective of Skopos Theory
}

\author{
Ning Li \\ School of Foreign Languages, Guangdong Pharmaceutical University, Guangzhou, PR China \\ Email address: \\ Glorialeesmile@163.com

\section{To cite this article:} \\ Ning Li. A Study of English Translation of Six Chapters of A Floating Life from the Perspective of Skopos Theory. International Journal of \\ Applied Linguistics and Translation. Vol. 5, No. 4, 2019, pp. 82-88. doi: 10.11648/j.ijalt.20190504.16
}

Received: October 22, 2019; Accepted: November 13, 2019; Published: November 19, 2019

\begin{abstract}
Chinese classical literature is the essence of Chinese traditional culture. With the revitalization of China, various western countries in the world have paid great attention to Chinese history, culture and literature. Many excellent Chinese classical works were translated into English. Shen Fu's (沈複) Fu Sheng Liu Ji (《浮生六記》) is a representative work of Chinese classical literature and Lin Yutang's (林語堂) version Six Chapters of A Floating Life is well-received in the English world. This paper attempts to study the application of the Skopos theory with the basic analysis on the translation strategies which is not including domestication and foreignization, but also translation techniques, such as amplification, deletion and annotation from the perspective of theoretical structure. Besides the basis of different translation strategies and techniques using in Lin's translated version Six Chapters of A Floating Life, the author also try to analyze and illustrate from the perspective of Skopos theory, translators should have the concern of taking the target readers' demands into consideration firstly before translating texts, for the target readers have their own cultural backgrounds, expectations to translated texts and requirements of cross-cultural communication.
\end{abstract}

Keywords: Chinese Classical Literature, Translation Strategies, Skopos Theory, Target Reader

\section{Introduction}

Chinese classical literature is the media of Chinese history, philosophy and culture as well as the spiritual sustenance for Chinese people. Therefore, English translation of Chinese classical literature plays a significant rule in the process of cultural exchange. Fu Sheng Liu Ji is an autobiographical novel written by Shen $\mathrm{Fu}$, a scholar in Qing Dynasty. In the novel, Shen described romantic and tranquil life with his wife, expressed love for her by showing his liking for truth, beauty and nature, while also described his unique taste in literature and art of traditional Chinese society. Just for the literary and artistic value, it was translated by Lin Yutang in 1935, and then become popular.

Being the most significant theory of the German School of function theory, Skopos theory focused on "aim" or "purpose" [2] of originally, which is regarded as a technical term for the purpose of translation. From the perspective of the basic theoretical structure, translators would to take the target readers' demands into consideration firstly before translating texts. It concentrates on the selection of various purposes in the process of translating, although target readers have their own cultural backgrounds, expectations to translated texts and requirements of cross-cultural communication.

\section{Literature Review}

\subsection{Chinese Classical Literature}

China, one of the four major ancient civilizations, has volumes of classical literature. Literature is not only using language to express meaning, but also a media to spread culture. Therefore, what is Chinese classical literature? This question is of vital without explicit definition until now, but the paper attempts to demonstrate some available opinions.

In principle, the conception of Chinese classical literature includes all the fundamental literature appearing in the cultural history. Actually, the definition is so broad that some restriction and regulation should be explained further in details. When Chinese classical literature concerns for something cultural in spirit, it is supposed to emphasize on the primary characteristic of Chinese culture. On one hand, the 
comprehensive horizon should be persisted on by covering subjects of literature, history and philosophy and taking cultures of Confucianism, Buddhism and Taoism into account. It's a narrow cognition that Chinese classical literature only contains works in literature. For instance, The Songs of Poems, The Songs of the South, the poems of Tang Dynasty, the lyrics of Song Dynasty, prose of Pre-Qin Dynasties sages, fables and novels of Ming and Qing Dynasty and Yuan poetic drama certainly count as Chinese classical literature [8]. Besides such literature works, some artistic works, such as the representatives in the theory of calligraphy and painting, as well as history and philosophy works all belong to Chinese classical literature. On the other hand, China is a country with multi-nations. For a long time, minorities cultures in history are ignored and subordinate to Han nationality culture. Only studying Han nationality history and culture with the ignorance of other outstanding cultures goes against the objective fact of Chinese culture. Therefore, scholars' attention should also be paid to minorities cultures when translating Chinese classical literature.

\subsection{Translation of Chinese Classical Literature}

Translation of Chinese classical literature has a long history. It is initiated by Chinese translators and later becomes a particular learning field by western translators, such as a prestigious sinologist James Legee, Pearl S. Buck, David Hawkes and so on. Inspiring achievement are made in the aspect of translation of Chinese classical literature and correlative study due to the enormous efforts of several generations. At the same time, there exist some problems both in theory and practice in translation of Chinese classical literature. The first thing worthwhile to talk about is how to think about and evaluate versions. It is a biased and controversial opinion that the versions of Chinese cultural classical literature by Chinese translators are easier to be understood by original language readers than that by target language translators. The prejudice possibly caused by the ignorance of translation techniques and strategies, divergence in translation theory and translators' language ability. How to escape from Chinese-culture-centered theory and eliminate the prejudice in language, culture and psychology still remain the unsolved questions. In addition, it's difficult for translators to get the target language readers' response to adjust their translations to the specific situation [1]. Some versions of Chinese classical literature are not accepted by the foreign people but popular in China for English learners to learn translation strategies and techniques. These versions tend to be out of the eyesight of foreign scholars and make them refuse to learn Chinese further. Therefore, only when translators obtain all the response information both in original language and target language could they push for development of English translation of Chinese classical literature and put forward Chinese culture.

\subsection{English Version of Six Chapters of a Floating Life}

It is an autobiographical novel written by Shen Fu in Qing
Dynasty, which was comprised of Wedded Bliss, The Little Pleasures of Life, Sorrow, The Joys of Travel and another two missing (or perhaps not complete) chapters, Experience and Way of Living. The original title of his novel stems from $\mathrm{Li}$ Bai's poem, "The floating life is like a dream, and how brief the enjoyment is!" [11]. Until now, Six Chapters of A Floating Life is still characterized by true purity, creativity and authenticity without traces of pondering over expressions and literary techniques. This creativity is firstly reflected in its subject matter. The author wrote the pleasure and happiness of spouses in an affectionate but straightforward style, showing the simple but sincere love between husband and wife. In the history of Chinese literature, there are many poems depicting love, but most of them either depict love affairs in the royal palace, or write love tragedies under the oppression of authority and feudal ethical code, or write love of confidantes and immature and lingering love between young men and women while seldom involve love of couples. Later in 1935, Lin Yutang translated Six Chapters of A Floating Life and his version was published in West Wind Publishing House. Lin is the first Chinese writer who directly wrote in English and enjoyed a high reputation in English world. As Lin's typical couplet goes, "One mind seeks the learning of ancients and moderns; two legs straddle the cultures of East and West" [11].

\subsection{Overview on Skopos Theory}

Great progress has been made in western translation theory studies since the middle $19^{\text {th }}$ century. As a translation theory established by German linguists, the Skopos theory provides translators with a different view. It concerns the selection of various purposes in the process of translating.

\subsubsection{Three Main Rules}

Skopos means "aim" or "purpose" in the Greek and it was adopted to the translation theory by Hans Vermeer in 1970s. Before that, Katharina Reiss proposed that the ideal translation was "integral communicative performance" and "moved translation theory beyond a consideration of lower linguistic levels" [2]. Then, Reiss and Vermeer formulate into Skopos rules: "“an interaction is determined by (or is a function of) its purpose' and 'the skopos can be said to vary with the recepeint"' [7]. The skopos rule expresses that the expectant translation of target language receivers should have the equivalent function in the translated context and culture. The aim of the translation determines the translation procedure, namely, "the translation purpose justifies the translation procedure" or "the end justifies the means" [2]. There are three understanding of the skopos: the first is fundamental and prime purpose of translator; the second one is the communicative purpose of the translation; the last one is goals that the translation strategies will achieve. Usually, the skopos refers to the third meaning, which means the translator determines the communicative purpose of the translation. The initiator of translation will have reasons for special need of the translation, for instance, the environment in which target readers are and the translation is used. In other words, these reasons mean the translation requirements. The translation 
demands have shown the translator which kind of translation is needed, although that does not mean that the translator must accept all of these requirements in a passive position without translators' subjectivity. The translator can go in for determining the purpose of the translation, especially when the initiator is indeterminate about it due to lack of professional scholarship or other reasons. In this case, the translator can associate with the initiator and deduce the purpose of the translation from concrete translation conditions. However, the skopos also refers to the purpose that the text means to achieve, that is, the communicative purpose.

Except for the skopos rule, there are other two rules of the theory: coherence rule and fidelity rule. The former means that the translation should be understood by the target readers and be meaningful in the culture of the target language and the communicative environment in which the translation is used. The text is regarded as the information provider by target readers. Schaffner explained it in this way: "the target text must be sufficiently coherent, allowing the purposeful users to understand the translation, providing their particular background knowledge and situational circumstances" [1]. In accordance with the skopos rule, the translator merely chooses the information which fascinates him and then transforms the information into the target language, making it become the new information provider and following their purpose. During the process, the primary rule that the translator should accept is the intra-lingual coherence rule. Because it is by language processing that the translation provides information with the target reader, the translation should be loyal to the source text. In that case, the translator should follow the fidelity rule. The rule only states that there must be coherence between the source text and the translation [5]. That is to say, the translation should keep faithful to the translated text in the content, form and style and the degree of faithfulness is determined by the aim of the translation as well as translator's interpreting of the original text.

\subsubsection{Significance of Skopos Theory}

The emergence of the theory has broken the traditional and narrow translation rules. It is a theory that analyzes the translation from a communicative perspective. Moreover, it makes the translation out from the restriction of the domination of source-text-oriented, which states that the translation is a behavior based on the original text, with the purpose and result and this behavior must be finished through negotiation. In addition, in the traditional translation theory, the translator always serves as the media, even a negative imitator hose main work is to ensure the translation is faithful to the original text both on meaning and literary form. In order to achieve the faithfulness, the translator has to study the source text and comprehend it totally and find the same or similar expressions in the target language. Nevertheless, according to the Skopos theory, translators have gotten the role as a passive imitator and become a creator possessing full autonomy. Being faced with the task of translation, the translator has the right to determine the manner and strategy in the process of translation. Therefore he can create greater translation works that are more acceptable to target readers. What's more, the Skopos theory provides the field of translation with a new standard to justify the translation work. If the translation reaches the communicative purpose, it could be called an excellent translation and vice versa.

\section{Analysis on Lin Yutang's Translation from the Pespective of Skopos Theory}

\subsection{Skopos Rule}

According to the Skopos theory, "the primary principle determining any translation process is the purpose of the overall translation action. Each text is produced for a given purpose and should serve this purpose" [2], therefore, Lin's translation purpose determines his translation process. He chooses translation techniques and strategies which facilitate the realization of culture communication and promotion of Chinese culture. Especially in the era in which most western scholars were dissatisfied with the reality and turned their learning direction from their own culture to Chinese culture, Lin's choice of Six Chapters of A Floating Life was inspired by the cultural atmosphere.

Meanwhile, the most direct motivation for Lin Yutang to translate it into English, is to make the lovely couple known by foreign people. As Lin mentioned in his postscript of the novel, "I have always taken fancy to the book Six Chapters of A Floating Life, therefore I decided to express my desire to translate it into English, and to make people on this world know the lovely life of a Chinese couple, who are quiet in minds and are indifferent to fame or material gain." (Lin postscript). What makes the translator deep-impressed is that the couple "lived the spirit of truth and beauty and the genius for resignation and contentment to the characteristic of Chinese culture" [3]. In his translation process, he tries his best to present the original description of couple's life and make the target language readers have the same feeling like Chinese readers as far as possible. Lin's translation practice keeps accordance with the skopos principle through the whole translation process. Here are some examples following:

\section{Example 1:} [6]

Source Text: “吳下相傳謂之 “收眼光”; 延羽士作法......”

Translation: "We called this in Soochow 'choosing the spirit's eyes'. People also used to invite a Taoist monk to recite incantations "[3]

In this example, “羽士” refers to a person who regards Taoism as conviction. In ancient China, it is usually invited to drive the ghost of the dead away when someone died. Although monk derives from Christianity, it is also loosely used to point to a man who has the similar religious belief. Here, it is translated into "Taoist monk", which not only preserves the Chinese culture content, but also makes target language readers understand it more easily. This translation embodies the skopos rule.

Example 2: 
Source Text: “䲨案相莊廿有三年.....” [6]

Translation: "And so we remained courteous to each other for twenty-three years of our married life like Liang Hung and Meng Kuang [of the East Han Dynasty]......" [3]

In this translation section, “䲨案相莊” refers to the story of Liang Hung and Meng Kuang, with the figurative meaning of the mutual respects and love between husband and wife. Lin's translation of the allusion could be easily accepted by source language users but it's difficult for language receivers to understand the politeness between husband and wife like treating a guest. In order to appeal the target readers, Lin Yutang uses annotation and explanation to introduce the two figures of the story. In this way, the translator not only provides ample cultural information but satisfies target readers' curiosity.

Example 3:

Source text: “王怒餘以目.......蓮鉤撥入池中” [6]

Translation: "Wang looked at me angrily.......and kicked them into the pond." [3]

Lin's translation, his word choosing “蓮鉤” refers to deformed feet of women in ancient China, which caused by the cruel custom that young women are required to bind their feet because tiny feet represent women's elegance and beauty. The connotative meaning of “蓮鉤” is hard for translators to express. Here, Lin omits the cultural information to avoid obscurity for target readers with the aim of making foreign readers become interested in Chinese culture.

Example 4:

Source text: “今則天各一方, 風流雲散, 兼之玉碎香埋, 不堪回首矣” [6]

Translation: "Today these friends are scattered......the woman I loved is dead, like broken jade and buried incense......" [3]

In Chinese culture, "Jade" is an image with the symbolic meaning of purity and beauty. In order to convey deep and sincere affection of departed wife, a broken jade is used to compare with the death of Yun written by Shen Fu. Although there is no similar usage in English, the translator still retain this figurative image in consideration of spreading Chinese culture and increasing western readers' interests.

\subsection{Coherence Rule}

Based on the Skopos theory, coherence rule means the translation should be coherent to the target receivers' cultural backgrounds and knowledge. In other words, translators are supposed to take acceptability of target readers, as while as the environment and conventional expression into consideration. When translating Chinese classical literature into English, translators should consider how to deal with the cultural differences in the view of English readers. Here are some examples in Lin's translation.

Example 5:

Source text: “惟長幼皆能琵琶矣” [6]

Translation: "Except that all of them, old and young, could play the p'ip'a." [3]

As a part of Chinese traditional culture, "p'ip'a" is an unique musical instrument which without equivalent word in
English. At that time, Lin Yutang tries to search the transliteration to impress the English readers. The version remains the original culture through foregrounding.

Example 6:

Source text: “又在揚州商家見有虞山遊客攜送......惜乎 明珠暗投” [6]

Translation: "Once I also saw at the home of a merchant at Yangchow...... but this was like casting pearls before swine" [3]

“明珠暗投” is an allusion of Records of the Grand Historian with the literal meaning of putting the brilliant pearls in the darkness and meanwhile with the figurative meaning of providing valuable things with people who can't appreciate its worth [13]. The boxwood and cypress are so rare potted miniature landscapes in ancient China that they are usually appreciated by refined scholars. But in the Chinese text, the two pots are carried by a wealthy but mean merchant, whose social status are inferior to officials and scholars in ancient society. Lin's version makes it easier for receptors to understand the basic meaning in the condition of knowing no knowledge about Chinese history.

Example 7:

Source Text: “餘戲題其簽曰 ‘錦囊佳句’, 不知天壽之機 此已伏矣。”[6]

Translation: "I wrote playfully on the label of this book of poems the words: 'Beautiful Lines in an Embroidered Case', and did not realize in this case lay the course of her short life." [3]

It's not difficult for Chinese readers to understand why the author used the expression of Chinese of “錦囊佳句” to remark on Yun's poems. It's an allusion happening in Tang dynasty that a poet $\mathrm{Li} \mathrm{He}$ often went out on a donkey and if he had the inspiration of a new poem, he would write them down and put the paper in his embroidered case [14]. However, the talented poet died at the age of 27 . In the source text, Shen Fu thought his compliment was not a good sign because of Yun's death at her young ages. Lin Yutang only translates the literal meaning of “錦囊佳句”, which would cause the target readers unknown about the figurative meaning of "Beautiful Lines in an Embroidered Case" and the relationship between the compliment and Yun's short life. In this way, the purpose of introducing Chinese cultural information to receptors will be obstructed because of loss of real meaning of the story. This is an example which doesn't meet readers' taste and should be avoided.

\subsection{Fidelity Rule}

As mentioned above, the fidelity rule refers to "inter-textual coherence" between the source text and the target text. Briefly, it means that the target text should be loyal to the original version. Style is a vital factor in the process of translation guided by the fidelity rule. Nida once mentioned, "A good translation should not only convey the what the original work writes, but also the style of it" [4]. Six Chapters of A Floating Life is an autobiography written in the perspective of first person. In order to be consistent with the original, Lin increases subject "I" throughout the whole English version. 
Furthermore, the characteristic of Lin Yutang's version is faithful to the concise and colloquial language style of the original book. Here is the example,

Example 8:

Source Text: “少焉一輪明月以上林梢, 漸覺風生袖底, 月到波心，俗慮沉懷爽然頓釋”。[6]

Translation: "After a while, the moon had already arisen from behind the forest, and the breeze was playing about our sleeves, while the moon's image sparkled in the water, and all worldly cares were banished from our breasts." [3]

The author portrays us the picture of poetic Chinese expression as “月上林梢，清風拂袖，水光月影”, which includes artistic images with difficulty to be translated into another language [15]. However, Lin translates such a beautiful scene into English without losing the sense of beauty. Taking the word "play about" as an example, it vividly describes the same tranquil and idyllic scenery and conveys the carefree feeling. This example shows Lin's success on obeying the fidelity rule of the Skopos theory. Moreover, for instance, the original expression of “曾經滄海難為水, 除卻 巫山不是雲” [12] is a line selected from Yuan Chen's poem, which contains the poet's deep love and sorrow for his departed wife. It literally means that people who have came to the vast sea will not be appealed by any water while people who have seen the clouds in the Yangtze Gorges will not be astonished by any clouds. In this poem, the poet uses the images of water and clouds to express his love for his life. Shen $\mathrm{Fu}$ states that he would never love others except for Yun by quoting Yuan Chen's poem. Lin Yutang retains the two images in translation to be in accordance with the original text as "it is difficult to be water for one who has been the great seas, and difficult to be clouds for one who has seen the Yangtze Gorges" [3]. Apparently, Lin persists in the fidelity rule of Skopos theory by maintaining the original style and spirit.

\section{Strategies and Techniques on the Translation of Six Chapters of a Floating Life}

\subsection{Translation Strategies}

American translation theorist, Lawrence Venuti put forward the strategies of domestication and foreignization in The Translator's invisibility (1995). Before that, the two strategies was first mentioned by German linguists and translation theorist Friedrich Schleiermacher. In his lecture On the Different Methods of Translating, he mentioned "Either the translator leaves the author in peace as much as possible and moves the reader toward him, or he leaves the reader in peace as much as possible and moves the writer toward him" [9]. The translation strategy concerns for faithfulness to the original content, form and style, which involves the fidelity rule of Skopos theory. The paper attempts to analyze the application of domestication and foreignization in Lin's translation.

\subsubsection{Domestication}

Domestication is a translation strategy making target text closely conform to the target language culture, which can minimize the strangeness of the original works. It demands translators to adjust translation techniques to convey the linguistic and cultural differences of the original context for the target language readers. $\mathrm{Xu}$ Yuanchong again stated that literary translation involved a competition between the two languages and cultures, and a translated work could surpass the original if it made full use of the favorable factors in target language or if it could "recreate" the original. Besides, $\mathrm{Xu}$ Jianping and Zhang Rongxi conclude: "In order to achieve cross-cultural communication in E-C translation, foreignization should be used with supplementary domestication. While in C-E translation, domestication should be used as much as possible" [10]. This strategy concerns readers' acceptability and response and communication aim, which coincides the skopos rule and the coherence rule of Skopos theory.

In Lin's translation, he used the Chinese “神” into "God” by the strategy of domestication. Based on the theory, the version transforms unfamiliar thing to native thing with the aim of decreasing receivers' feeling of strangeness about Chinese culture. It's seen that God could be easily understood by target readers in the cultural background of Christianity to make them not flinch learning Chinese culture.

\subsubsection{Foreignization}

Foreignization is also a common translation strategy retaining information from the source text and breaking the conventions of the target language without losing original meaning. Different from domestication, foreignization remains the language features and cultural characteristics of the source language without removing the cultural difference. By means of foreignization, translators can make target language readers know more about the culture of the source language. For example the original text of Shen $\mathrm{Fu}$, “若必考 訂其文法，是責明於垢鏡矣” [6], “mirror (鏡) ” is an important image in Chinese culture containing essential cultural information, and could be derived from the illusion “以銅為鏡” of Taizong in Tang Dynasty. Here, Shen Fu used a metaphor of comparing readers' overstrict exploration to "looking for brilliance in a tarnished mirror". In the process of translation, Lin remains this image and metaphor and simultaneously expresses the original meaning by means of foreignization [9]. Lin takes the translation purpose, readers' cultural background and inter-contexual coherence into account, which is a good example to show the Skopos theory.

\subsection{Translation Techniques}

\subsubsection{Amplification}

Amplification, or addition, is a translation strategy that translators are supposed to add necessary expressions or information but without increasing any meaning not from the original text. By means of supplying necessary words in our translation work, strategy of amplification makes the translation text correct and clear. Common words to be added 
are verbs, adjectives, nouns, linking words and so on.

Example 9:

Source text: “牆外仰矚, 見從樹交花, 嬌紅嫩綠, 依山 傍水, 極饒幽趣”。[6]

Translation: "Looking in from the outside, I saw there was a profusion of trees and flowers in charming red and green made all the more beautiful by a stream in front and a hill at the back." [3]

In that the original excerpt is a sentence without subject and necessary connective device, Lin Yutang adds the subject "there", the cohesive phrase "looking in from the outside" and some orientation prepositions "in front" "at the back". Guided by the Skopos theory, Lin thinks about reader's language style, which differs from Chinese language features. Chinese is a parataxis language with many four character phrases and loose sentences without connective devices. Therefore, Lin uses the strategy of addition to be in accordance with his translation purpose of making foreigners know and accept Chinese culture.

\subsubsection{Deletion}

Deletion is another translation strategy for translators to delete some unnecessary words or information in version. Six Chapters of A Floating Life belongs to Chinese classical literature, some details in Chinese traditional culture do not demand to be understood for target readers. This is the reason why Lin adopts strategy of deletion to bridge the gap between two cultures. Here is an example, “時吾父稼夫公 在會稽幕府.....受業於武林趙省齋先生門下。先生循循 善誘..... [6]. In traditional Chinese culture, “公” and “先生” are both honorific titles to venerable and exalted men and teachers in ancient China [14], but are less and less used in modern Chinese. Omitting such expressions doesn't decrease the completeness of original meaning, so Lin employs the strategy of deletion to bring cordial feeling to target readers with the translation of "At that time my father Chiafu was in the service of the Kueich'i district government...... w was under the tutorship of Chao Shengtsai of Wulin [Hangchow.] Chao was a very kindly teacher...... [3]. What's more, the Chinese addressing of husband and wife usually be expressed as “君” (a honorific appellation to men) and “妾”(a humble title to women). It is easy for Chinese readers to understand why Yun says in such a humble manner. In ancient China, men are superior to women because of the feudal ethical code. If Lin translates them directly, the version must confuse English readers without Chinese history knowledge. Just translating “君” and "妾” into equal address "You" and "I" by the device of deletion makes western readers well understand.

\subsubsection{Annotation}

It's self-evident that annotation is a significant translation strategy especially when it refers to translation of Chinese cultural class literature. There exist many Chinese idioms and allusions, conventional expressions, knowledge of culture and history and other something unique in Six Chapters of $A$ Floating Life. When translating such expressions, the strategy of noting and explaining in the text facilitates target readers to comprehend Chinese culture to realize the communicative goal. Meanwhile, annotation is a way of keeping version realize the same style and manner.

Example 10:

Source text: “倩繪一像，一手挽紅絲，一手.....” [6]

Translation: "It was a picture of the old man holding, in one hand, a red silk thread [for the purpose of binding together the hearts of all couples] and in the other....." [3]

In this example, the original expression in Chinese “倩繪一 像” refers to “月下老人”, a Chinese mythological figure who manages marriage in the earth by recording the couple's names on the book and make them bind together by attaching beloved couples with red threads. However, most of English readers can not catch the mythology and figurative meaning of "a red silk thread" [15]. Through annotation of the figure image, Lin's version conforms to the three rules of Skopos theory.

\section{Conclusion}

As an indispensable part of Chinese literature and culture, Chinese classical literature plays a significant role in the process of spreading Chinese culture, while adapting the theoretical basis of Skopos theory of Chinese cultural classical literature is necessarily.

Through analyzing Lin Yutang's version of Six Chapters of A Floating Life translation with the structure of Skopos theory, there would be several major findings, firstly, Lin Yutang always takes cultural differences of two languages into account in the process of translation. Secondly, the three rules of the theory could be used to guide Chinese to English translation, especially Chinese classical literature. Thirdly, according to the Skopos theory, the translator should think about English readers' demands and enhance the acceptance of translation. Finally, in order to hit the communicative target and spread Chinese culture, such translation strategies including domestication, foreignization, amplification, deletion and annotation could help translators proceed to transform language in the basis of the theory.

Meanwhile, there are still limitations of the research. On one hand, with the case study on Lin Yutang's English version, to some extent, can not cover all the features of different versions and offer ample analysis to support application of Skopos theory in Chinese classical literature translation. On the other hand, there is no doubt that the theory is a new learning direction for Chinese classical literature translation, but the ignorance of diversities on translation studies in this field or make translation become a mere activity with definite purpose are still appeared. For these limitations, the awareness of suggestions for further research can be illustrated as following: First, there are many English versions of Chinese and western learners, the further studies should concentrate on comparison of different versions. In addition, the translators should enhance subjectivity in the process of translation in the consideration of connotative cultural and communicative factors not just with definite purpose. 


\section{References}

[1] Baker, Mona. Encyclopedia of Translation Studies [M]. London: Routledge, 1998.

[2] Christiane, Nord. Translating as a Purposeful Activity Functionalist Approaches Explained [M]. Shanghai: Foreigner Language Education Press, 2002.

[3] Lin Yutang. Six Chapters of A Floating Life [M]. Beijing: Foreign Languages Study and Research Press, 2009.

[4] Nida, Eugene. Language and Culture-Contexts in Translating [M]. Shanghai: Shanghai Foreign Language Education Press, 2001.

[5] Reiss, Katharina \& Hans Vermeer. Grundlegung einer allgemeinen Translationtheorie [M]. Tubingen: Niemeyer, 1984.

[6] Shen Fu. Fu Sheng Liu Ji [M]. Tian Jin Press, 2016.

[7] Shuttleworth, Mark \& Cowie, Moira. Dictionary of Translation Studies [M]. Manchester: St. Jerome, 1997.

[8] Shao Youxue. New Perspective on Chinese Intellectual History of Translation [M]. Beijing: China Social Science Press, 2018.

[9] Venuti, Lawrence. The Translation Studies Reader [M]. New York: Routledge, 2004.

[10] Wang Haixia. Appreciation of Lin Yutang's English Version of Six Chapters of A Floating Life [J]. Journal of Hanjiang University, vol 3, 95-98, 2003.

[11] Wang Hongyin. Translation of Chinese Classical Literature [M]. Beijing: Foreign Languages Study and Research Press, 2009.

[12] Wang Huanchi. Specific Literary Words in Translation and the English Version of Six Chapters of A Floating Life [J]. Journal of Foreign Languages, vol 2, 104-106, 2004.

[13] Wang Bingqin. History of Chinese Modern Translation Thoughts [M]. Shanghai: East China Normal University Press, 2018.

[14] Xu Jianping \& Zhang Rongxi. Domestication and Foreignization in Cross-cultural Translation [J]. Journal of Chinese Translation, vol 5, 71-75, 2003.

[15] Zhao Xifang. Translation and Modern China [M]. Shanghai: Fudan University Press, 2018. 